\title{
Digestive And Tracheal System of Menopon Gallinae (Phthiraptera: Amblycera) Infesting Poultry Bird (Gallus Gallus Domesticus)
}

\author{
Surman Arya ${ }^{1} \cdot$ Suneel Kumar Singh ${ }^{2 *}$ \\ ${ }^{1}$ Department of Zoology, PDBH, Govt. P.G. College, Kotdwara (Garhwal), Uttarakhand \\ ${ }^{2}$ Department of Science, Modern Institute of Technology, Dhalwala, Rishikesh (Uttarakhand), India \\ *Corresponding Author Email id: drsuneelkumarsingh@gmail.com
}

Received: 04.11.2020; Revised: 25.03.2021; Accepted: 30.05.2021

OSociety for Himalayan Action Research and Development

\begin{abstract}
The digestive and tracheal system of a poultry shaft louse, Menopon gallinae (Phthiraptera: Amblycera) has been studied in greater details. Alimentary canal of louse was dissected out along with crop under stereozoom binocular microscope. Entire alimentary canal of M. gallinae was found more or less straight and has three basic parts (fore-gut, mid-gut and hind-gut) while crop-teeth was present in the crop. The posterior end of crop contains 20-30 well developed crop-teeth arranged in a single arced plate, in comb-like fashion. Mid-gut was found as simple tube and contributes nearly one half of the total length, while the hind-gut was marked by the opening of Malpighian tubules in alimentary canal. The heart of $M$. gallinae is of simplest kind, one chambered bulbous structure having three pairs of laterally placed ostia and supported by four pairs of alary muscles. In the tracheal system there were seven pairs of spiracles occurred on the terga of M. gallinae. The first pair of spiracle was found located close to legs while remaining six abdominal spiracles occur from segment $3^{\text {rd }}$ to $8^{\text {th }}$. The degree of tracheation of various visceral organs has also been noted.
\end{abstract}

Keywords: Menopon gallinae $\bullet$ Poultry shaft louse $\bullet$ Amblycera $\bullet$ Phthiraptera $\bullet$ Digestive system $\bullet$ Tracheal system

\section{Introduction}

Preliminary information on anatomy of lice (Phthiraptera) has been provided by Strindberg (1916a, 1916b, 1918 \& 1919), Blagovestchensky (1931 \& 1959) and Clay (1949), while Seguy (1951) and Eichler (1963) have tried to generalize the available information on anatomical peculiarities of some lice. Anatomical features of different organ systems of three species [one Ischnocera (Lipeurus lawrensis tropicalis) and two Amblycera (Laemobothrion percnopteri and Menacanthus eurysternus)] have already been worked out (Srivastava, 1974; Saxena, 1979; Chandra, 1986). Haug (1952), Waterhouse (1953), Saxena \& Agarwal (1981) and Navio et al. (1986) have provided specific information on digestive system of selected species. Wilson (1933), Crutchfield \& Hixson (1943), Agarwal et al. (1983), Saxena et al. (1985), Trivedi et al. (1990),
Singh et al. (2010) and Kumar et al. (2017) added valuable information about haematophagous nature and feeding habits of some amblyceran and ischnoceran avian lice species. Some publications dealing with structure and role of cropteeth of Mallophaga have also appeared from time to time (Cummings, 1913; Blagovestchensky, 1949; Agarwal \& Saxena, 1978; Saxena \& Agarwal, 1979; Srivastava \& Agarwal, 1981; Saxena et al., 1995).

The present report deals with morphological features of digestive and tracheal system of an amblyceran poultry louse, Menopon gallinae.

\section{Material and Methods}

Fresh lice were obtained directly from hosts. Furthermore, regular supply of lice was ensured 
by maintaining them in vitro condition $\left(35 \pm 1^{\circ} \mathrm{C}\right.$, $75-90 \%$ R.H., pinfeather diet) in incubator. Extremely sharp entomological pins (fabricated by rubbing on fine sand paper) were used for dissection. The lice were dissected, under a stereozoom binocular microscope in Insect Ringer's solution (Ephrussi \& Beadle, 1936). After removing the bulk of fat bodies, a few drops of aqueous Bouin's fluid was added to get proper differentiation of internal organs.

The structure and arrangement of crop teeth was investigated by taking out the crop which was dehydrated, stained in acid fuchsin. The contents were teased out in clove oil and mounted in D.P.X.

To study the haemocytes, blood films were prepared from haemolymph drop obtained by cutting the legs, or by making an incision in the terga of live lice that had been properly cleaned. The air dried blood films were directly stained in Leishman's stain or first fixed in methanol and then stained in Giemsa's or Wright's stain. But the smear fixed in aqueous Bouin's fluid and stained with haematoxylin - eosin gave better cytological picture of the blood cells than those obtained after staining with Leishman's or Giemsa's stains.

The spiracles were clearly seen in the lice treated with $10 \% \mathrm{KOH}$ solution (for $10-12 \mathrm{hrs)} \mathrm{washed}$ in water containing few drops of acetic acid, stained in acid fuchsin, dehydrated, cleared in clove oil and mounted in D.P.X. The tracheal system was examined by the techniques suggested by Srivastava \& Sinha (1965) and Brown (1968). Brown's technique (the use of ethyl acetate vapours) did not give satisfactory results and the method suggested by Srivastava \& Sinha (1965) proved useful in tracing out the fine tracheal tubes.

\section{Observations}

\section{Digestive System}

The alimentary canal of $M$. gallinae is more or less straight tube conventionally divided into foregut, mid-gut and hind-gut.

The fore-gut:- The fore-gut comprises the pharynx, oesophagous and crop. The mouth leads into short muscular pharynx which continues into thin tubular oesophagous. The later expands into crop before leading into the mid-gut. The crop is a conspicuous, pear-shaped structure (also visible through tergal covering of freshly moulted well fed specimens). It contributes the major portion of fore-gut and occupies anterior half of the abdominal cavity. The sac-like crop posteriorly ends in a somewhat conical structure (proventricular region) (Figure $1 \& 2$ ).

The proventricular region of the crop shows the presence of teeth-like chitinous structure (seen clearly in stained mounts of alimentary canal). The crop teeth are situated at the posterior end of crop (in somewhat semicircular fashion) and are lodged in single arced plate, present in dorsal wall, projecting ventrally in the lumen. Each tooth is long spine like structure (sometimes curved) measuring $24-30 \mu$ in length (free projecting part). The basal part of the teeth is comparatively broader. There are $25-30$ teeth in arced plate. Thus, the entire organization of crop teeth resembles a comb or sieve which serves as effective device to prevent the entry of any large particle into the mid-gut. The crop being elastic in nature is able to store plenty of feather barbules (which are taken one by one and get arranged in lengthwise manner). 


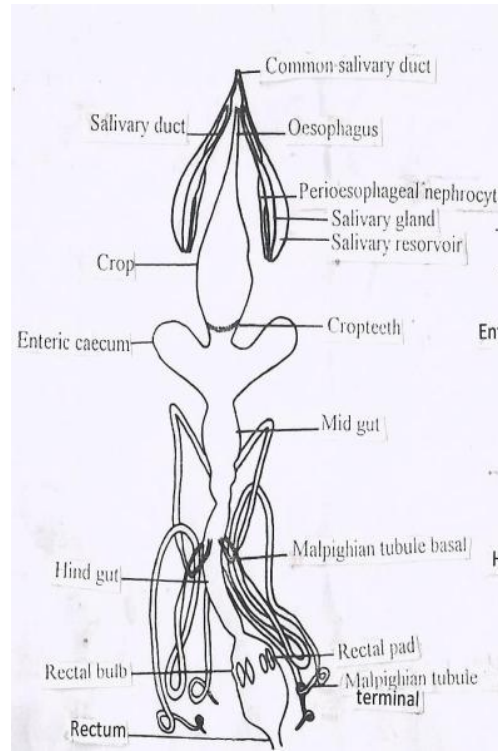

Figure 1

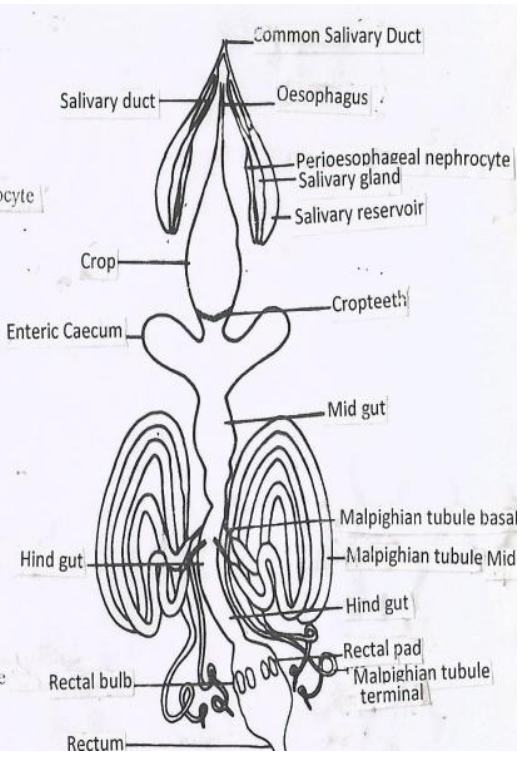

Figure 2

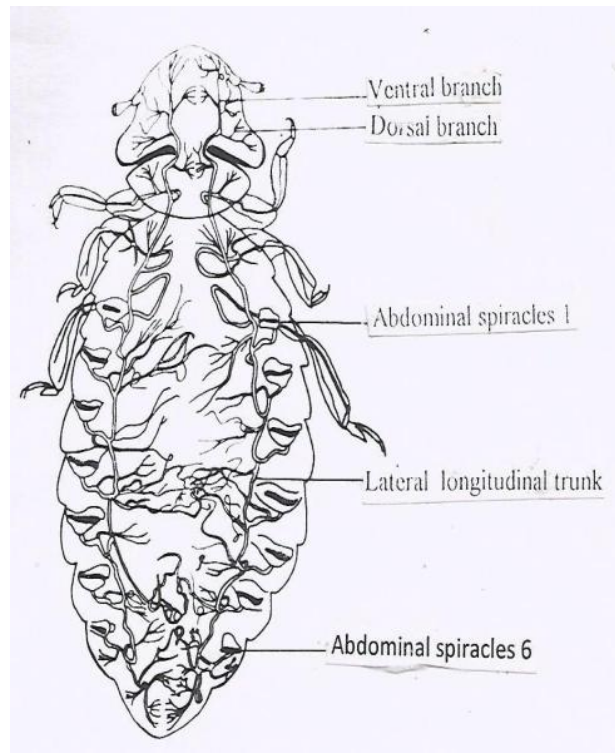

Figure 3

Fig 1: Alimentary canals of Menopon gallinae Male; Fig 2: A.C. of Menopon gallinae Female and Figure 3: Tracheal system of Menopon gallinae

Furthermore, the crop undergoes regular antiperistaltic movements, followed by peristaltic movements arising at opposite end. Due to these contractions the tips of barbules are forced to strike against the group of crop teeth and this may cause some mechanical trituration. However, the rest of the crop wall is completely devoid of any spine / bristle like structure (as noted in few other species).

The mid-gut:- It is simple tube and contributes nearly one half of the total length. Furthermore, the anterior two third of the mid-gut has greater diameter than the posterior one third region. Anteriorly, the mid-gut is extended into diverticular expansions known as enteric caecum, one on either side of crop. Each caecum is a blind tubular structure, showing transverse constrictions. The mid-gut narrows down to hindgut, at posterior end (Figure $1 \& 2$ ).

In case of freshly fed lice, the mid-gut appears red to brown (due to presence of host blood in it). However, the blood corpuscles of host could not be detected in mid-gut (as seen in crop) (disintegrated by digestive degradation process). The junction of mid-gut and hind-gut is marked by the presence of four Malpighian tubules.

The hind-gut:- The commencement of hind-gut is marked by the opening of Malpighian tubules in alimentary canal. Morphologically, the hind-gut is divisible into three distinct parts, the ileum, rectal bulb and rectum. The nature of three components is similar in both sexes. The ileum is a short simple tube which dilates to form the rectal ampullae. The later contains six rectal papillae (glands) located in whorl. The rectal papillae are in form of six well marked, elevated rectal pads. On the other hand, rectum is a narrow short tube opening outside by anal aperture (Figure $1 \& 2$ ).

The salivary apparatus:- A pair of salivary glands and their ducts, a pair of salivary reservoir and their ducts constitute the salivary apparatus of M. gallinae. The salivary glands are present on either side of the crop. Each gland is an elongated, slightly curved, opaque-white structure. Each 
gland gives out a very fine salivary duct from its apical end. The reservoirs are also fairly long tubular structures placed slightly obliquely along lateral margins of crop (in association with salivary glands). A thin duct emerges from anterior end of each reservoir and unites to salivary duct of its side. Later, the two ducts finally unite to form a common salivary duct (that opens into salivarium). Furthermore, a chain of nephrocytes (termed perioesophageal nephrocytes) is found associated with each salivary reservoir (Figure $1 \& 2$ ).

The Malpighian tubules:- Four long blind Malpighian tubules arise from the junction of mid-gut and hind-gut (one dorsally, one ventrally and two laterally). Infect, entire haemocoel on lateral side of alimentary canal (from crop to rectal bulb) is occupied by these tubules which are held in position by tracheae and muscles. The terminal end of these tubules lies near the posterior region of the rectal bulb. The nature of Malpighian tubules differs in two sexes and moreover, the females posses slightly longer tubules. In both the sexes, each Malpighian tubule is divisible into three parts, a basal, a middle and terminal. The nature of basal and terminal portion remains similar in two sexes (thin, tubular) but that of middle portion varies. In case of female, the middle part is more wide and opaque. No pigment is found in any part of Malpighian tubule, in both sexes (Figure $1 \& 2$ ).

Tracheal System:- Seven pairs of spiracles occur on the terga of $M$. gallinae. First pair is located close to legs. Six abdominal spiracles occur from segment $3^{\text {rd }}$ to $8^{\text {th }}$. They are located on the anterolateral margins of terga (Figure 3). Each stigmata is a big sized (measuring 0.004 to $0.007 \mathrm{~mm}$ ), somewhat lip shaped structure. All the spiracles not are alike. Spiracle present in $4^{\text {th }}$ to $6^{\text {th }}$ abdominal segments are comparatively bigger.

Tracheae are disposed in two main lateral longitudinal trunks (Figure 3), which run from head to $8^{\text {th }}$ abdominal segment. They are not straight tubes but follow a sinuous course throughout its length. They are not connected with each other by transverse commissures in any region of the body (as found in other species, studied so far). On entering the head each trunk converges for short distance and then, diverges, dividing into dorsal and ventral branch. A fine branch arises from dorsal branch tracheate pharynx and fore-head. The ventral branch runs anteriorly giving out several branches. One branch arises from each sides tracheates the suboesophageal ganglion and pharynx. These branches approximate touch each other but fails to form head commissure. Several fine tracheae arising from ventral branch run towards margins of head (Figure 3).

In thorax, the lateral longitudinal trunk lies slightly deeper in muscles. Prothoracic commissure has not been detected. One fine branch arising from longitudinal trunks in prothoracic region runs inwards to tracheate prothoracic ganglion and pharynx. Another branch arising from each trunk turns outwards and goes to prothoracic legs. In meso-thorax and metathorax, one branch arises from longitudinal trunks and turns outwards to tracheate the second pair of legs. Finer branches arising from this branch tracheate oesophagous, meso- and metathoracic ganglion. Another branch arising from the main trunk near first abdominal segment runs inwards, makes a big loop and then turns out towards first pairs of leg, beneath first stigmata. The tracheae in abdomen follow metameric arrangement. In $3^{\text {rd }}$ to $8^{\text {th }}$ abdominal segment, a short stigmatic branch arises from stigmata and connects it to lateral longitudinal trunk. From base of stigmatic branch, a ventral branch arises, which tracheates sternal, pleural and tergal muscles. One or two branches arising from longitudinal trunk in each segment run inwards to tracheate the visceral organs present in corresponding segment (Figure 3).

All the ganglia (viz., the brain, the suboesophageal, pro - meso and meta - thoracic 
ganglia) are richly supplied with tracheae. The meta - thoracic ganglion is particularly tracheated. The degree of tracheation varies in different regions of alimentary canal. Though the anterior part of fore - gut receives only a few tracheae, the posterior region of crop and salivary apparatus are found to be richly tracheated. Most of the mid - gut is poorly tracheated, except the enteric caeca which receive profuse tracheation. The hind - gut is also heavily tracheated, specially the rectal pads. Testes, the posterior parts of vesicular apparatus and anterior part of ejaculatory duct are poorly tracheated in comparison to the anterior pat of vesicular apparatus, posterior part of ejaculatory duct and male genitalia. Ovarioles and posterior part of vagina receive good supply of tracheae in comparison to the lateral and median oviducts. The heart and its alary muscles are richly tracheated in comparison to aorta.

\section{Discussion}

The general morphology of alimentary canal of $M$. gallinae does not show any remarkable departure from general plan observed by the workers in other amblyceran species studied so far (Blagovestchensky, 1949; Haug, 1952; Waterhouse, 1953; Srivastava, 1974; Chandra, 1986). However, the salivary apparatus and Malpighian tubules show some differences from earlier studied species. Except the Malpighian tubules, the morphology of digestive tract of two sexes remains quite similar. However, in case of L. percnopteri, division of Malpighian tubule (in the three portions) occurs only in female and not in males (Srivastava, 1974). Furthermore, the any portion of tubule does not exhibit pigmentation as observed in other species (Blagovestchensky, 1949). The nephrocyte occurring in association with salivary gland do not form chain of cells as seen in ischneceran L. lawrensis tropicalis (Agarwal \& Saxena, 1981a). The nature of crop teeth of M. gallinae seems to be similar to that of other amblyceran species studied in the past (Cummings, 1913; Blagovestchensky, 1949; Waterhouse, 1953; Srivastava \& Agarwal, 1981; Chandra, 1986; Saxena et al., 1995). However, Srivastava \& Agarwal (1981) have noted the presence of bristle like structures on the lateral margins of crop teeth. The crop teeth of $M$. gallinae do not bear such bristles. Furthermore, Agarwal \& Saxena (1978) have recorded the presence of spines in the entire cropwall (in addition to crop teeth). The crop wall of $M$. gallinae is devoid of such spines. In Ischnocera, the teeth are small and sparse and occur on the anterior end of crop, which is a tadpole shaped blind sac-like structure (Cummings, 1913; Waterston, 1926; Blagovestchensky, 1949; Waterhouse, 1953; Agarwal \& Saxena 1978; Saxena \& Agarwal, 1979). They mainly act as triturating agents (when the tips of barbs are rubbed against them during the contraction of crop). On the other hand, in Amblycera, cropteeth are better developed and occur in form comb of teeth at the posterior end. According to Waterhouse (1953), they are mainly responsible for the sieving of crop contents. Srivastava \& Agarwal (1981) and Chandra (1986) held them responsible for trituration of feather barbules also. In $M$. gallinae, the cropteeth mainly function as sieving apparatus and their role in trituration seems to be little.

Spiracles of $M$. gallinae are quite big sized lip shaped structures (as compared to other phthirapterans). The disposition of tracheal tubules and tracheation of abdominal parts resembles to other species (Harrison, 1915; Srivastava, 1974; Agarwal \& Saxena, 1981b; Chandra, 1986). However, the occurrence of blind stigmatic branch (in first two abdominal segments) has not been noted in M. gallinae as found in two amblycerans studied by Srivastava (1974) and Chandra (1986). Furthermore, presence of transverse tracheal tubes connecting 
two lateral longitudinal trunks in head, pro- mesometa thorax and $8^{\text {th }}$ abdominal segments cound not be detected in $M$. gallinae (as found in $L$. percnopteri and L. lawrensis tropicalis by Srivastava, 1974 and Agarwal \& Saxena, 1979).

\section{Acknowledgement}

Authors are thankful to Principal, Government P. G. College, Kotdwara (Garhwal) for laboratory facilities and Forest Research Institute, Dehradun for library consultation.

\section{References}

Agarwal GP and Saxena AK (1978) The cropteeth and spines of the crop of Lipeurus lawrensis tropicalis Peters (Phthiraptera : Ischnocera). Indian J. Parasitol. 2(1): 27-28.

Agarwal GP and Saxena AK (1979) Tracheal system of poultry lice, Lipeurus lawrensis tropicalis Peters 1931 (Phthiraptera : Ischnocera). Biol. Bull. India. 1(3): 23-30.

Agarwal GP and Saxena AK (1981a) The perioesophageal nephrocytes of some ischnoceran Mallophaga

(Phthiraptera). Angew. Parasitol. 22: 104106.

Agarwal GP and Saxena AK (1981b) Further observations on the freely circulating haemocytes of Liperus lawrensis tropicalis Peters (Phthiraptera : Ischnocera). Curr. Sci. 50(12): 551.

Agarwal GP, Saxena AK and Chandra S (1983) Haematophagous behaviour of Menacanthus eurysternus (Mallophaga, Amblycera). Angew Parasitol. 24(1): 55-59.

Blagovestchensky DI (1931) K anatomii vlasoeda morskoj svinki Gyropus ovalis N. Paaz. Sborn. 2: 181-228.

Blagovestchensky DI (1949) Stroenie piscevaritelnoj sistemy puchoedov $\mathrm{v}$ svjasi $\mathrm{s}$ ich pitanjem. Paraz. Sborn. (Leningrad). 11: 229-245.

Blagovestchensky DI (1959) Nasekomyje puchoedy, Tom I, vyp 1. Fauna SSSR $($ Moskva $)+\quad$ Leningrad, n.s. 72 .
Brown NS (1968) Methods for the study of tracheal system and copulatory apparatus in Menacanthus stramineus. Ann. Ent. Soc. Amer. 61(3): 788-789.

Chandra S (1986) Studies on ecology of Phthiraptera of common Myna, Acridotheres tristis and various organ system of Menacanthus eurysternus (Phthiraptera : Amblycera). Ph.D. Thesis, B.H.U., Varanasi, India.

Clay T (1949) Piercing mouth-parts in the biting lice (Mallophaga). Nature. 164: 617

Cummings BF (1913) Note on the crop in the Mallophaga and on the arrangement and systematic value of the crop-teeth. Ann. Nat. Hist. 12: 266-270.

Crutchfield CM and Hixson H (1943) Food habits of several species of poultry lice with special reference to blood consumption. Florida Entomol. 26(4): 63-66.

Eichler Wd (1963) In: Dr. H.G. Bronns klassen und ordnungen des tierreichs, (b) Phthipratera: 1. Mallophaga akademische verlagsgeslschaft geest \& portig K.g. Leipzig. 5(3), 7(b): 1-290.

Ephrussi B and Beadle GW (1936) A technique of transplantation for Drosophila. Amer. Nat. 70: $\quad 218-225$.

Harrison L (1915) The respiratory system of Mallophaga. Parasitol. 8: 101-127.

Haug G (1952) Morphologische und hiostphysiologische untersuchungen an den verdauungsoranen der Mallophagen und Anopluren. Zool. Jb. Anat. 72: 302-344.

Kumar S, Ahmad A, Ali R and Kumar V (2017) A note on the haematophagous nature of poultry shaft louse, Menopon gallinae (Amblycera: Phthiraptera). J. Parasit. Dis. 41(1): 117-119.

Navio AMF, Cruz MDS, Parra SM, Rodriguez RB, Lopez MD and Cruz MCS (1986) Digestive system of Bovicola caprae Gurlt, 1843 (Insecta : Mallophaga). Cah. ORSTOM. Ser. Entomol. Med. Ent. Parasitol. 24(4): 251-254.

Saxena AK (1979) Studies on various organ systems of poultry lice, Lipeurus lawrensis tropicalis Peters (Phthiraptera: Ischnocera). Ph.D. Thesis, B.H.U., Varanasi, India. 
Saxena AK and Agarwal GP (1979) On the presence of "cropteeth" and spines in three species of ischnocerous lice (Phthiraptera). Proc. Nat. Acad. Sci. India. 49(B) 1:29-32.

Saxena AK and Agarwal GP (1981) Digestive system of poultry lice, Lipeurus lawrensis tropicalis (Phthiraptera: Ischnocera). Angew. Parasitol. 22: 147-156.

Saxena AK, Agarwal GP, Chandra S and Singh OP (1985) Haematophagous nature of Trinoton querquedule (Phthiraptera: Amblycera). Angew. Parasitol. 26: 205-208.

Saxena AK, Surman, Kumar A and Singh SK (1995) Cropteeth of poultry shaft louse, Menopon gallinae (Phthiraptera: Amblycera). Bioved. 6(2): 219-222.

Seguy E (1951) Ordre des mallophages. In: P.P. Grasse, Traite de Zoologie, masson et cie, Paris. $\quad 10(2): 1341-1364$.

Singh SK, Arya S, Singh SK and Khan V (2010) Feeding and reproductive behaviour of pigeon slender louse, Columbicola columbae (Phthiraptera, Insecta, Ischnocera), J. Appl. Nat. Sci. 2(1): 126-133.

Srivastava RK (1974) Studies on the anatomy and histology of various organ systems of

Laemobothrion percnopteri (Gervais) (Mallophaga: Amblycera). Ph.D. Thesis, B.H.U., Varanasi, india.

Srivastava RK and Agarwal GP (1981) Structural details and role of the cropteeth of phthirapteran parasite, Laemobothrion percnopteri (Gervais) (Mallophaga: Amblycera) infesting Indian scavenger vultures. Proc. Nat. Acad. Sci. 51(B) III: 245-249.

Srivastava VS and Sinha PK (1965) On the respiratory system of the adult male and larva of Centrococus insolitus Green (Hemiptera: Cocoidea). Entomol. 280-287.

Strindberg H (1916a) Zur entwicklungsgeschichte und anatomie der mallophage. Z. Wiss. Zool. 115: $\quad 382-459$.

Strindberg H (1916b) Studien uber die ectodermalen Teile der Geschlechtsorgane einigar Mallophagengattungen. Zool. Anz. 48: 84-87.
Strindberg H (1918) Typstudien uber die Geschlechtsorgane einiger Mallophagengattungen. Z. Wiss. Zool. 117: 591-653.

Strindberg H (1919) Die Geschlechtsorgane von Ornithobius bucephalus Giebel und Goniodes falcicornis N. Zool. Anz. 50: 219235.

Trivedi MC, Sharma S, Rawat BS and Saxena AK (1990) Haematophagous nature of an amblyceran phthirapteran,

Menacanthus cornutus Schommer, infesting poultry bird, Gallus domesticus L. in India. J. Appl. Entomol. 110: 107-111.

Waterhouse DF (1953) Studies on the digestion of wool by insects. IX. Some features of digestion in chewing lice (Mallophaga) from bird and mammalian hosts. Aust. J. Biol. Sci. 6(2): 257-275.

Waterston J (1926) On the crop contents of certain Mallophaga. Proc. Zool. Soc. London. 96: $1017-1020$.

Wilson FH (1933) A louse feeding on the blood of its host. Science. 1933; 77(2003):490.

$$
\text { ******* }
$$

